\title{
Autoimmunity in transfusion babesiosis: a spectrum of clinical presentations.
}

\author{
Jay H Herman \\ Thomas Jefferson University \\ Saleh Ayache \\ Thomas Jefferson University \\ Danuta Olkowska \\ Thomas Jefferson University
}

Follow this and additional works at: https://jdc.jefferson.edu/pacbfp

Part of the Medical Cell Biology Commons, and the Pathology Commons Let us know how access to this document benefits you

\section{Recommended Citation}

Herman, Jay H; Ayache, Saleh; and Olkowska, Danuta, "Autoimmunity in transfusion babesiosis: a spectrum of clinical presentations." (2010). Department of Pathology, Anatomy, and Cell Biology Faculty Papers. Paper 60.

https://jdc.jefferson.edu/pacbfp/60

This Article is brought to you for free and open access by the Jefferson Digital Commons. The Jefferson Digital Commons is a service of Thomas Jefferson University's Center for Teaching and Learning (CTL). The Commons is a showcase for Jefferson books and journals, peer-reviewed scholarly publications, unique historical collections from the University archives, and teaching tools. The Jefferson Digital Commons allows researchers and interested readers anywhere in the world to learn about and keep up to date with Jefferson scholarship. This article has been accepted for inclusion in Department of Pathology, Anatomy, and Cell Biology Faculty Papers by an authorized administrator of the Jefferson Digital Commons. For more information, please contact: JeffersonDigitalCommons@jefferson.edu. 


\title{
As submitted to: \\ Journal of Clinical Apheresis
}

\author{
And Later published as:
}

"Autoimmunity in Transfusion Babesiosis:

A Spectrum of Clinical Presentations"

\section{Volume 25, Issue 6, 2010, Pages 358-361 \\ DOI: 10.1002/jca.20262}

\author{
Jay H. Herman*, Saleh Ayache, Danuta Olkowska \\ Transfusion Medicine Department, Thomas Jefferson University Hospital, \\ Philadelphia, PA
}

*Correspondence to:

Jay H. Herman, MD

Transfusion Medicine Department

8220 Gibbon Building

Thomas Jefferson University Hospital

111 S. $11^{\text {th }}$ Street

Philadelphia, PA 19107

Telephone: 215-955-8244

Fax: 215-923-9387

Email: jay.herman@jefferson.edu

Key words: erythrocytapheresis, hemolysis, autoantibody, babesia 
Abstract: Transfusion-acquired babesiosis can be an asymptomatic or self-limited febrile hemolytic illness in a healthy host. A persistent, relapsing and/or fulminant course with the development of life threatening complications may be seen in immunocompromised or splenectomized patients. As in malaria, erythrocyte parasitemia is often associated with non-immune hemolysis, and can be treated with erythrocytapheresis. Just as warm autoantibodies have been reported in malaria infection, the development of autoantibodymediated immune hemolysis has been reported in babesiosis. We treated a previously healthy male with multiple injuries from a motor vehicle accident necessitating massive transfusion. His hospital course was complicated. Late in the hospitalization, his blood smear revealed Babesia microti, confirmed by PCR study and serology. Specific antiobiotic therapy was begun, and severe hemolysis from a high parasite burden required red blood cell exchange which led to rapid abatement of the hemolysis. He had a positive DAT (IgG with a pan-reactive eluate) but no serum autoantibody. This persisted for 10 days following cessation of hemolysis, and became negative while still on antibiotics while his parasite burden became undetectable. Reports of autoimmunity caused by babesiosis often have severe hemolysis from their autoantibodies, but our case shows that immune hemolysis from autoantibodies in babesiosis is not a constant finding. The nature of the autoantigen is unknown. 


\section{Introduction}

Babesiosis is a zoonotic protozoan disease transmitted primarily by genus Ixodes ticks. Babesia microti and Babesia divergens are the two most common species of babesia infecting humans in the United States [1]. These parasites can infest erythrocytes and cause malaria-like illness. There has been an increased awareness of transfusion-acquired babesiosis (TAB) in the last two decades, with more than 50 cases reported since 1980 [2]. Several factors contribute to the risk of TAB transmission. Most donor infections are asymptomatic, and currently there is no licensed donor screening assay for Babesia [3]. Tick borne pathogens can survive in refrigerated [4, 5] or frozen-thawed [6] blood components.

Infections with Babesia can run a varied clinical course. Healthy hosts may have an asymptomatic or self-limited febrile illness. Both adults and children who are immune compromised or have undergone splenectomy are at risk to develop severe symptomatic infections with malaise, myalgias, fever, chills and sweating. These patients may have a chronic persistent, relapsing or fulminant course [1] and develop life threatening complications, including acute respiratory distress syndrome [7], disseminated intravascular coagulation and acute renal failure [8]. Human babesiosis is often associated with non-immune hemolysis from the erythrocytic parasites, and occasionally thrombocytopenia in more severe cases.

Many infections or inflammatory diseases may cause immune dysregulation; and bacterial, viral and parasitic pathogens have been known to stimulate autoantibodies that 
crossreact with similar antigens on erythrocytes. Autoimmunity to red blood cells in babesiosis has been documented in humans $[9,10]$ just as it has been reported in malaria infection $[11,12,13]$.

\section{Case Report}

A 61 year old, Group O, Rh negative male, with a negative antibody screen was in a motor vehicle accident on August 5 in which he sustained multiple injuries including cervical burst fracture at $\mathrm{C} 7$, multilevel thoracic spinal compression fractures, scapular fracture, multiple rib fractures and severe intraabdominal injuries. During transport to our facility he became hypotensive, and responded to pressors, fluid resuscitation and emergency blood transfusion. Exploratory laparotomy revealed mesenteric hematoma, hemoperitoneum, splenic laceration requiring splenectomy, and liver laceration. The hemorrhage was controlled and while in the OR the patient underwent application of cranial traction to treat his unstable cervical fracture. He received a total of 19 units of packed red cells (12 $\mathrm{Rh}$ negative, $7 \mathrm{Rh}$ positive), $2 \mathrm{Rh}$ negative apheresis platelets, 18 units of FFP and 10 units of cryoprecipitate while he had active bleeding during his first 36 hours. Three days later (day +4 ), he returned to the OR for abdominal washout, removal of packs, wound closure and placement of feeding gastrostomy tube and required no transfusion. On day +6 he underwent anterior decompression and stabilization of the cervical fracture requiring no blood intraoperatively, but 2 units of Rh negative red cells were given in the post-op period. His hospital course and recovery were complicated by multiple episodes of aspiration pneumonia, urosepsis and central 
line infection. He was treated with multiple antibiotics, including Zosyn, Ciprofloxacin, Vancomycin and Tobramycin during this time.

Additional red blood cell transfusions were needed beginning on day +41 because of worsening anemia. Compatibility testing revealed he had developed alloantibodies to D and $\mathrm{E}$ but he did not have a positive DAT or evidence of a serum autoantibody. His Rh typing was Group $\mathrm{O}$, Rh negative with no mixed field appearance at that time. On day +51 , a weakly positive DAT for IgG was detected. An eluate (Elukit method) reacted with all D-E- cells tested. The serum again did not demonstrate an autoantibody or additional alloantibody. His LDH was $1052 \mathrm{U} / \mathrm{L}$ and reticulocyte count $9.3 \%$ (absolute 291,000 B/L). To evaluate whether he had a drug antibody, studies at a reference laboratory demonstrated no reactivity using the two antibiotics he was still receiving which have most commonly been implicated, Zosyn and Vancomycin.

Between day +41 and day +51 , his hemoglobin dropped from 9.6 to $7.2 \mathrm{gm} / \mathrm{dL}$ despite the transfusion of 3 units of Rh negative red blood cells and the reticulocyte count remained elevated (absolute 292,000 B/L). The serum haptoglobin was $<6 \mathrm{gm} / \mathrm{dL}$ and a new serum alloantibody was detected, anti-C. The anti-C was not revealed in repeat elution studies, although the DAT was still positive for a pan-reactive antibody.

On day +54 , examination of his blood smear revealed numerous red cells with intracellular parasites suggestive of Babesia microti, subsequently confirmed by PCR and serology. Retrospectively, blood smears retrieved from the previous few days revealed scattered B. microti infected RBCs that had been overlooked. The level of parasitemia on day +54 was $7.8 \%$. Treatment with Gentimycin and Azithromycin was initiated, but hemolysis continued despite several days of antibiotic treatment. On hospital day +57 , he 
had worsening symptomatic hemolytic anemia, with $\mathrm{Hgb}$ dropping to $5.6 \mathrm{gm} / \mathrm{dL}$, increasing reticulocytosis and symptomatic tachycardia, hypoxia and dyspnea. Red blood cell exchange with 8 units of $\mathrm{Rh}$ negative red blood cells was performed with rapid clinical improvement following the exchange transfusion. Evidence of hemolysis abated rapidly. The exchange dramatically reduced the parasite burden to $0.6 \%$ by the next day and to $<0.003 \%$ on day +63 . A blood smear on day +67 , ten days after the exchange, was clear of all parasites. The positive DAT for IgG persisted for 10 days following cessation of his hemolysis and then became nondetectable. The patient continued to improve clinically and was eventually discharged home after completing his course of antibiotics. No further transfusion was required after the red cell exchange and his Hgb remained stable. His elevated reticulocytes began declining after the exchange and returned to normal within nine days.

\section{Epidemiology}

The patient was a retired state trooper who lived in central Pennsylvania. He denied a history of known tick bites and his only exposure to fields or wooded areas was a round of golf played a few weeks prior to his MVA. Given the usual 1-4 week incubation period for community acquired babesiosis, TAB was suspected given its later symptomatic onset. With the cooperation of our blood center, the infection was traced to one of the donors of the units used during the massive transfusion on August 5. High titer Babesia microti IgM antibody (IFA of 1:512) was found in a 4-month post-donation sample. This donor lived in southern New Jersey, a known area of Babesia microti 
infestation. The PCR assay of the follow-up donor sample was negative and no residual material from the original donation could be recovered. The case was reported as TAB associated with the transfusion of red cells, most probably from the donor with high titer IgM antibodies.

\section{Discussion}

The incubation period for TAB may be longer than after a tick bite [1], although the delayed onset in our patient may also have been due to the antibiotics he had been on, some of which had partial effectiveness against B. microti. The severity of TAB in our patient can be attributed to his asplenic state, as has been reported, and may have become more clinically apparent as his antibiotic therapies were completed.

Our patient's positive DAT and apparent autoantibody could have been caused by delayed transfusion reactions from anti-D, anti-E and anti-C induced by the $\mathrm{Rh} d$ incompatible emergency transfusions on day 0 and day +1 . However, the time course of the serologic findings are much more compatible with this being TAB-associated autoantibody. Our patient's course of hemolysis was clearly different from the other cases of TAB associated autoantibody reported in the literature.

In a series of cases, Wolf et al, [9] reported that three of 30 patients with clinical and laboratory evidence of community acquired babesiosis, all asplenic, had positive DAT's due to IgG but not complement. Eluates prepared from the patients' red blood cells reacted with all cells but were markedly less reactive with $\mathrm{Rh}$ null cells. One of the patients developed marked hemolysis with $8 \%$ Babesia microti parasitemia following 
travel to an endemic area. She was treated with red blood cell exchange and developed anti-E and anti-c. She received multiple transfusions of antigen negative blood, but continued to have hemolysis, despite low parasitemia $(0.1 \%)$, and persistence of the autoantibody. This patient's continued immune hemolysis responded to treatment with steroids.

The second report of babesiosis with autoantibodies was described by Evenson, et al, [10]. A 47 year old transplant recipient who had been receiving immunosuppressive therapy for 8 years probably acquired babesia from a tick bite during travel to an endemic area. The patient was treated with antibiotics and red blood cell exchange and stabilized. Hemolysis improved transiently, but a few weeks after being discharged from the hospital he was readmitted with worsening parasitemia. The DAT was positive for IgG, but not C3. Red blood cell exchange was performed for the second time and his immune suppression therapy was changed. Over the next six weeks he had increasing paresitemia and another two episodes of worsening hemolysis with a positive DAT for both IgG and C3. He was treated with antibiotics and red blood cell and plasma exchanges. Hemolysis appeared to be due primarily to autoantibody rather than parasite burden. When the antibody was no longer detectable parasitemia increased from $<1 \%$ to $8.2 \%$ but he had no worsening of hemolysis. Continued treatment with Clindamycin, Atovaquone and Quinidine alone led to a drop in parasitemia. After two more months no parasites were detected in his red blood cells and the DAT was negative. This patient had persistent parasitemia, and his autoantibody contributed to hemolysis over four months, but disappeared before the eradication of infection. 
Our experience underscores that TAB may cause severe hemolysis which can be dramatically improved by exchange erythrocytopheresis. Our experience also underscores that TAB may cause the development of autoantibodies just as in community acquired babesiosis, but immune hemolysis is not a constant finding and the autoantibody may be transient and clinically innocuous.

\section{References}

1. Leiby DA. Babesiosis and blood transfusion: flying under the radar. Vox Sanguinis 2006;90:157-165.

2. Leiby DA. Babesia and other parasites. In: Brecher ME, editor. Bacterial and parasitic contamination of blood components. Bethesda (MD): American Association of Blood Banks; 2003. p 179-200.

3. Transfusion-transmitted Babesia. AABB Association Bulletin \#09-06, August 5, 2009.

4. McQuiston JH, Childs JE, Chamberland ME, Tabor E. Transmission of tick-borne agents of disease by blood transfusion: a review of known and potential risks in the United States. Transfusion 2000;40:274-284.

5. Mintz ED, Anderson JF, Cable RG, Hadler JL. Transfusion- transmitted Babesiosis: a case report from a new endemic area. Transfusion 1991;31:365-368.

6. Grabowski EF, Giardina PJV,Goldberg D, et al. Babesiosis transmitted by transfusion of frozen-thawed blood. Ann Intern Med 1982;96:466-467.

7. Stowell CP, Gelfand JA, Shepard JO, Kratz A. Case 17-2007: A 25 -year old woman with relapsing fevers and recent onset of dyspnea. N Engl J Med 2007;356:2313-2319. 
8. Dorman SE, Cannon ME, Telford SR $3^{\text {rd }}$, Frank KM, Churchill WH. Fulminant babesiosis treated with clindamycin, quinine and whole-blood exchange transfusion. Transfusion 2000;40:375-380.

9. Wolf CFW, et al. Autoimmunity to red blood cells in Babesiosis. Transfusion $1982 ; 22: 538-539$.

10. Evenson DA, Perry E, Kloster B, Hurley R, Stroncek DF. Therapeutic apheresis for babesiosis. J. Clin. Apheresis 1998;13:32-36.

11. Lefrancois G, Bouvet E, Le Bras J, Vroklans M, Simonneau M, Vachon F. Antierythrocyte autoimmunization during chronic falciparum malaria. Lancet 1981;2:661664.

12. Daniel-Riberio CT, Zanini G. Autoimmunity and malaria: what are they doing together? Acta Trop 2000;76:205-221.

13. Butcher G. Autoimmunity and malaria. Trends Parasitol 2008;24:291-292. 